\title{
EDUCAÇÃO AMBIENTAL NA CONSCIENTIZAÇÃO FLORESTAL E FAUNA- BRAVIA PARA AS NOVAS GERAÇÕES EM CHÓKWÈ-MOÇAMBIQUE
}

Munossiua Efremo Macorreia ${ }^{1}$

Resumo: Despertar a consciência às novas gerações da escola primária do primeiro grau (EP1), constitui um algo novo e indispensável, pois possibilita estimular aos aprendizes a participarem com rigor como agentes/gestores ativos na tomada das resoluções ambientais capazes de assumirem novas responsabilidades e práticas, visando executar um tipo de desenvolvimento que cultive uma relação harmoniosa cuidadosa e a preservação florestal e fauna-bravia dentro dos limites impostos pela natureza. Foram entrevistados 10 professores correspondentes a uma amostra de 3 pessoas dos quais dois professores e uma professora e 50 aprendizes com amostra de 15. Todos foram interrogados sobre conteúdos relacionados a contribuição da Educação Ambiental no contexto da conscientização florestal e fauna-bravia, na perspectiva de responder a seguinte pergunta: Quais as dificuldades que os professores consideram relevantes para à inclusão da Educação Ambiental nos programas curriculares, desenvolvendo a Educação Ambiental no âmbito da conscientização florestal e fauna-bravia? Assim, O presente estudo tem como objetivo: Investigar a forma como a Educação Ambiental está sendo implementada na escola primária do primeiro grau do segundo bairro em Chókwè, visando identificar quais as dificuldades que os professores deparam para à inclusão da Educação Ambiental dentro do contexto da conscientização florestal e fauna-bravia nos programas curriculares, desenvolvendo a consciência ambiental nas crianças com idade de 7 à 14 anos. Face a isso, os resultados revelam à ausência de ferramenta tanto pedagógica, quanto de capacitação de professores, o que justificaria que os mesmos não praticam suas atividades como facilitador, impossibilitando o aprendiz atuar como agente ativo do processo. Logo, sugere-se que a escola busque métodos adequados que possibilitam à incorporação da Educação Ambiental dentro do contexto da conscientização florestal e fauna-bravia nos programas curriculares, na perspectiva de construir conhecimetos que visem à conscientização dos aprendizes frente às problemáticas ambientais atuais.

Palavras-chave: Educação Ambiental; Educação Infantil; Preservação.

${ }^{1}$ FUNIBRE-Universidade Internacional e Instituto Agrario de Chokwe.

E-mail: efremomunossiua@yahoo.com.br 


\section{Introdução}

A Educação Ambiental no âmbito do desenvolvimento da consciência ambiental das novas gerações na preservação da floresta e fauna-bravia, em cada local no mundo planetário, deve constituir um instrumento capaz de participar ativamente na mediação necessária entre culturas, comportamentos, desenvolvendo consciência crítica que constroem valores sociais,

conhecimentos, habilidades, atitudes e competências, trazendo para a humanidade a necessidade de repensar sua forma de vida, seu cotidiano e a preservação do meio ambiente.

Assim, as ações de Educação Ambiental no âmbito de desenvolvimento da consciência florestal com a sua fauna-bravia, são de extrema relevância dentro do contexto escolar à medida que provoca processo de mudanças sociais e culturais que visam construir conhecimentos capazes de inverterem à crise ambiental e à urgência em mudar os padrões de uso dos bens ambientais, tomando decisões credíveis a seu respeito.

É neste âmbito, que aparece o Reigota (1998, p. 43-50), ao afirmar que:

é na prática pedagógica cotidiana que a Educação Ambiental, poderá oferecer subsídios importantes que possibilitam as novas gerações a entenderem e refletirem efetivamente que o uso inadequado dos recursos florestais e faunísticos pode afetar a qualidade de vida na terra planeta.

Assim, é fundamental que cada aprendiz desenvolve suas capacidades que permitem a construção de um ambiente sustentável e socialmente justo. Para isso, a Educação Ambiental no contexto de desenvolvimento da consciência florestal com a sua fauna-bravia, deve ser transmitida de forma sistemática e transversal em todos os níveis de escolaridades, assegurando a participação de todos na resolução da tomada das decisões credíveis que possibilitam a identificação, fiscalização, monitoramento e proporcionar as alternativas de ensinar os aprendizes as metodologias eficazes nas quais os seres racionais e irracionais sejam permanentemente valorizados. É a partir deste pressuposto, que Dias (2003), afirma que:

A Educação Ambiental no âmbito de desenvolvimento da consciência das novas gerações na preservação da floresta e fauna-bravia, deve participar ativamente na motivação do homem, visando adquirir novos valores, mentalidades e atitudes necessárias para lidar com questões e problemas ambientais e encontrar soluções sustentáveis que possibilitam romper com a cultura dominante para uma nova convivência social baseada na educação, conscientização. Para isso, o respeito é fundamental, pois o meio ambiente, só irá respeitar o homem se houver respeito recíproco. E o homem só respeitará o meio ambiente se respeitar a si mesmo. 
É nesta contextualização, que a partir da experiência vivida enquanto militar da contra intergência militar das Forças Armadas de Defesa de Moçambique, com auxílio da entrevista semidireta através do contacto direto com os aprendizes, pais e encarregados de educação, a comunidade em geral, sobretudo professores, pude constatar ausência da Educação Ambiental, desenvolvendo a Educação Ambiental no âmbito da conscientização florestal com sua fauna-bravia nos programas curriculares na escola primária do primeiro grau (EP1) do primeiro bairro da cidade de Chókwè em Moçambique.

Ela, é ensinada por meio de disciplina como ciências sociais e geografia. O que justificaria que as novas gerações com idades compreendidas entre 7-14 anos, concluam o ensino primário sem conhecimento, experiência e determinação que os facilitam atuar de forma individual e coletivamente na resolução da problemática ambiental do presente e do futuro.

Perante a situação verificada acima, surgem-nos o seguinte problema de investigação: Quais os problemas que os professores consideram relevantes para à inclusão da Educação Ambiental nos programas curriculares, desenvolvendo a Educação Ambiental dentro do contexto da conscientização das novas gerações na preservação florestal e fauna-bravia na escola primária do primeiro grau (EP1) do primeiro bairro da cidade de Chókwè?

Assim, o presente artigo tem como objetivo: Investigar a forma como a Educação Ambiental está sendo implementada na escola primária do primeiro grau (EP1), visando identificar quais os problemas que os professores deparam para à inclusão da Educação Ambiental no âmbito de desenvolvimento da consciência florestal com a sua fauna-bravia nos programas curriculares, desenvolvendo atitudes sustentável nas novas gerações com idade compreendida entre 7-14 anos.

Neste contexto, seria da responsabilidade dos professores das escolas primárias do primeiro grau (EP1), realizarem trabalhos pedagógicos na sala de aula junto com aprendizes, não apenas para cumprir as exigências do Ministério de Educação e Desenvolvimento Humano mais como forma de ensiná-los a tornarem gestores ativos do processo e responsável num ambiente ecológico sustentável que possibilite o desenvolvimento de uma prática social centrada para a preservação da floresta com a sua fauna-bravia.

A partir deste facto, na reflexão do Mayor (1998, p. 46), defende que:

Os professores devem levar a Educação Ambiental sustentável no contexto de desenvolvimento da consciência ambiental das novas gerações através de atividades de leituras, trabalhos escolares, pesquisas e debates referente ao manejo de ocupação do espaço, reflorestamento dos locais com maior degradação, na perspectiva dos aprendizes terem ferramentas básicas que possibilitam a preservação da floresta e faunabravia. 
Para isso, as Universidades sedeadas em Moçambique, devem contribuir na busca de soluções através dos seus programas educativas e novas metodologias, formulando políticas públicas participativas, que permitem as novas gerações, trabalharem individualmente e coletivamente, promovendo valores e comportamentos aceitáveis, na procura de soluções para problemas atuais, para prevenir o que possam aparecer futuramente.

\section{Contextualização teórica}

\section{Evolução histórica da Educação Ambiental}

Para compreender a evolução da Educação Ambiental no contexto da conscientização das novas gerações na preservação florestal e fauna-bravia, é fundamental partirmos do Mucelin (2004, p. 26), ao afirmar que:

A partir da segunda metade do século XVIII, a Europa deparouse com muitos problemas ambientais, principalmente o Reino Unido, por causa da intensificação do consumo de matéria dentre elas extrativista mineral, como carvão, petróleo e perca de tecido social, daí que o homem ouviu pela primeira vez a falar da desertificação, poluição dos solos, da água, degradação dos recursos florestais e faunísticos.

$\mathrm{Na}$ tentativa de encontrar alternativas viáveis na mitigação das problemáticas ambientais, que assolam quase todo o globo planetário, realizouse pela primeira vez na década 60 concretamente em março de 1965, a Conferência de Educação da Universidade de Keele, na Inglaterra, foi a partir dessa Conferência, que "a Educação Ambiental, é considerada como o único instrumento pioneiro capaz de conscientizar as novas gerações na preservação florestal e fauna-bravia e deveria ser defendida e fazer parte integrante da cultura de cada indivíduo ou coletivo" (MUCELIN 2004, p. 26).

Assim, em 1975, na Jogoslávia realizou o Congresso de Belgrado, que reuniu ambientalistas de 65 Países, promovido pela UNESCO, definiu as metas, os objetivos e princípios básicos voltados para a preservação do meio ambiente (floresta com a sua fauna-bravia), (...) (DIA, 2004).

A partir deste facto, surgiram várias Conferências Internacionais com a finalidade de discutir à problemática da sustentabilidade ambiental e a inserção da Educação Ambiental no âmbito da conscientização florestal com a sua fauna-bravia nos programas curriculares como disciplina interdisciplinar, na perspectiva de "despertar as novas gerações à participarem ativamente na luta pela preservação do meio ambiente e, consequentemente, de si próprio, construindo ações participativas na luta contra as atividades nefastas que perigam a regeneração florestal e fauna-bravia" (BARBIERI; SILVA, 2011). 
Assim, a Educação Ambiental no âmbito de desenvolvimento da consciência ambiental, é considerada como instrumento indispensável capaz de modificar o quadro crescente de degradação da floresta e fauna-bravia na região em estudo, "evitando violência ambiental, má distribuição de renda, mau uso dos recursos naturais, contaminação dos recursos hídricos, a geração do efeito de estufa e a redução da camada de ozônio e suas implicações sobre o equilíbrio térmico" (LOUREIRO et al., 2009).

A partir deste facto, segundo o Guarim (2002), declara que:

é urgente resgatar e construir um conjunto de ações e reflexões que propicie medidas coerentes que estabelecessem um conjunto de fatores naturais e humanos onde a Educação Ambiental tem de ser determinante nas práticas educativas, sociocultural baseado na interação entre pessoas, reconhecimento de valores e clarificações de conceitos, desenvolvendo capacidade individual e coletivo, habilidades, modificando as atitudes através da sua transmissão às jovens gerações em sala de aula ou da experiência pessoal do aprendiz, conduzindo a melhoria da qualidade de vida.

Assim, a Educação Ambiental, deve ser considerada como um campo de ação pedagógica, enfatizando a reforma do pensamento do homem, no sentido de construir conhecimento interdisciplinar, apontando a sala de aula como espaço privilegiado na mudança comportamental e a conscientização florestal e fauna-bravia das novas gerações da região em estudo, mostrando às crianças e jovens que preservar os recursos florestais e faunísticos não é um luxo, mas uma necessidade urgente se quisermos habitar nesta superfície planetária. Pois supomos haver uma necessidade extrema de uma Educação Ambiental sustentável.

\section{Resultados e discussão}

Com as preocupações de encontrar alternativas na solução em relação à problemática ambiental no distrito de Chókwè, foi realizado este trabalho com objetivo fundamental de esclarecer e conscientizar os professores e a comunidade em geral sobre a relevância de se trabalhar a Educação Ambiental no contexto da conscientização das novas gerações na preservação florestal e fauna-bravia.

Assim, o trabalho iniciou com a pesquisa bibliográfica, na perspectiva de perceber mais sobre a questão de Educação Ambiental no contexto da conscientização florestal e fauna-bravia das novas gerações, "explicando 0 problema a partir de referências teóricas publicadas em documentos" (CERVO; BERVIAN, 1983, p. 55). 
Diante disto, o trabalho foi realizado a partir da pesquisa exploratória, descritiva, de natureza qualitativa e quantitativa, visando identificar quais os problemas que os professores consideram relevantes para à inclusão da Educação Ambiental no contexto da conscientização das novas gerações na preservação florestal com a sua fauna-bravia nos programas curriculares, bem como perceber melhor a percepção, os conhecimentos, valores e opiniões, desenvolvendo as medidas pedagógicas que poderiam reverter 0 uso insustentável dos recursos florestais com a sua fauna-bravia.

A coleta de dados, foi analisada e separada de acordo com cada grupo: professores e aprendizes. Após análise dos dados foram socializados os resultados obtidos em uma palestra realizada na escola primária do primeiro grau (EP1) do primeiro bairro, com a presença de todos participantes da pesquisa. Foram distribuídos panfletos informativos, que refletem sobre os cuidados que devemos ter com os recursos florestais e faunísticos, que é constantemente destruídos sem a sua reposição para o aproveitamento da lenha, exploração de madeira, caça furtivo, etc.

\section{Análise dos Resultados obtidos com a Pesquisa de Campo}

$\mathrm{Na}$ pesquisa realizada com os professores e aprendizes da escola primária do primeiro grau (EP1), do primeiro bairro da cidade de Chókwè, todos foram interrogados e afirmam categoricamente que a Educação Ambiental no contexto da conscientização das novas gerações na preservação da floresta com a sua fauna-bravia, deve ser trabalhada diariamente na escola, na perspectiva de adequar a construção da consciência ambiental através de um ensino ativo e participativo, superando as dificuldades da insustentabilidade ambiental, contribuindo e incentivando significativamente as novas gerações para esse processo através da formação de cidadãos críticos e reflexivos capaz de atuar na complexa realidade socioambiental vivenciada na região em estudo. Houve variações de respostas conforme o Gráfico 1 e 2 (próxima página).

Neste pressuposto, o Ministério de Educação e Desenvolvimento Humano, deve proporcionar os cursos de capacitação dos professores das escolas primárias do primeiro grau (EP1), desenvolvendo currículo composto de disciplina que enfatizem o ensino de conteúdo de Educação Ambiental dentro do contexto da conscientização das novas gerações na preservação da floresta e fauna-bravia, oferecendo ferramentas pedagógicas para enfrentamento da problemática ambiental e evidenciando a relação harmoniosa entre o meio ambiente e os nossos hábitos e costumes, garantindo a proteção da flora com sua fauna-bravia e a nossa qualidade de vida, no presente e no futuro. 
Gráfico 1: Variações de respostas dos professores pesquisados

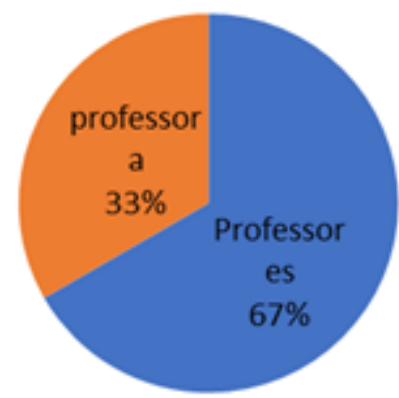

Nota: $67 \%$ dos professores pesquisados, afirmam que a Educação Ambiental dentro do contexto da conscientização florestal e fauna-bravia, deve promover um instrumento pedagógico capaz de construir conhecimento ambiental mais amplo, incentivando as novas gerações a problematizarem e pensarem sobre a sustentabilidade e a preservação do meio ambiente. 33\% da professora pesquisada, afirma que apesar de reconhecer a essência da Educação Ambiental no contexto da conscientização florestal e fauna-bravia a maioria dos professores ainda tem certas dificuldades de colocá-la em prática. O que justificaria que no processo do seu desempenho na sala de aula encontram vários obstáculos que dificultam o trabalho pedagógico como o caso: o tamanho da escola, número de alunos por cada professor, falta de material didático, falta de capacitação, vontade da diretoria de realmente implementar um projeto ambiental que irá alterar a rotina na escola. Fonte: Acervo próprio, 2019.

Gráfico 2: Variações de respostas dos aprendizes pesquisados.

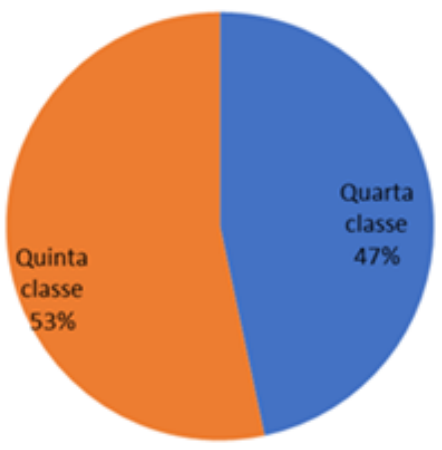

Nota: $47 \%$ dos aprendizes da quarta classe pesquisados, afirmam que a resolução dessa problemática ambiental, vivenciada na região em estudo, deve ser por meio de elaboração de materiais/imagens de divulgação, propaganda de aspectos ambientais e visita de estudo como estratégia pedagógica, porque facilita a socialização, criando condições coerentes mais próximo da realidade ambiental e que envolve os aprendizes em temática mais atuais do conhecimento humano, trazendo novas questões que possibilitem as novas gerações ter uma visão diagnóstico nas questões de preservação da floresta e fauna-bravia. Os $53 \%$ dos aprendizes da quinta classe interrogados, reconhecem a importância de se trabalhar às questões ambientais dentro do contexto da conscientização ambiental e tem sentimento a ver os recursos florestais com a sua fauna-bravia que nos protege a serem destruídos pelas queimadas descontroladas, visando a abertura de campos agrícolas, pastagens, caça, exploração da madeira, carvão vegetal (Figura 1), dentre outras atividades. Fonte: Acervo próprio, 2019. 


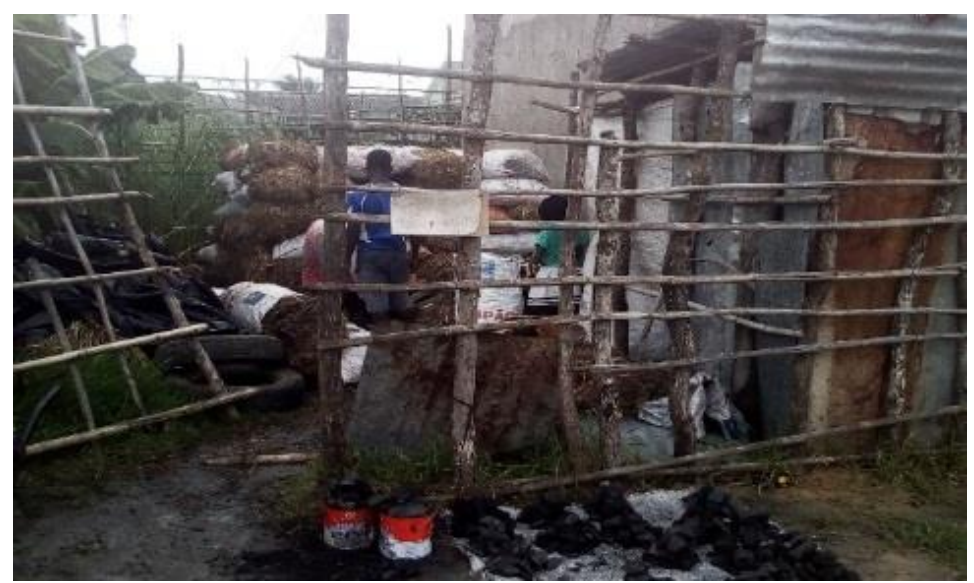

Figura 1: Instalação da venda de carvão.

Nota: A figura, ilustra uma instalação da venda de carvão, conseguindo através de destruição excessiva das diversas espécies florestais, influenciando negativamente a regeneração da biodiversidade com o seu meio ambiente e o processo do sistema da modificação hidrológico, destruindo a camada de ôzono e suas implicações sobre as mudanças climáticas na regiao planetária. Fonte: Acervo próprio, 2019.

É nesta contextualização, que Bonagurio (2009), defende que:

A escola deve constituir um local onde as novas gerações adquirem conhecimentos teóricos e práticos, contribuindo para a sustentabilidade ambiental. Assim, quanto mais cedo à conscientização sobre a degradação dos recursos florestais e faunísticos, maior será a responsabilidade, compreensão e a participação na tomada das decisões que possibilitam a formação dessas novas gerações de tal forma que tenham maior preocupação na construção de conhecimento formal e informal, possibilitando o desenvolvimento socioambiental e sociocultural onde cada cidadão sinta-se responsabilidade para a preservação dos recursos naturais.

Nesta perspectiva, a conscientização das novas gerações na preservação da floresta e fauna-bravia, deve ser realizada por meio de atividades práticas associadas aos problemas ambientais, pois as preocupações com o meio ambiente, passou a ter maior relevância a nível local, nacional, regional e internacional, devido as mudanças climáticas que enfermam o mundo em geral.

Para isso, as comunidades locais devem terem consciência ambiental que possibilitem o desenvolvimento sustentável, onde as novas gerações dentro da escola, devem atuarem como agente ativo do processo, o professor deve desempenhar a sua atividade de facilitador desse processo e os currículos escolares devem serem reformulados de maneira que haja a 
interdisciplinaridade, visando alcançar uma Educação Ambiental sustentável ecologicamente onde todos são motivados a atuarem na comunidade em prol do meio ambiente, propondo soluções adequadas para resolução de problemas relacionados à preservação florestal e fauna-bravia. afirmou que:

Considerado essa contextualização, na reflexão do Jacobi (2003),

A Educação Ambiental deve ser empregada nesse processo visto que utiliza propostas pedagógicas centradas na conscientização, mudança de comportamento das novas gerações, desenvolvimento das competências, capacidade de avaliação e participação dos educandos.

Assim, o desafio fundamental é preparar as novas gerações atuais para uma visão holística de mundo que leve a tomada de decisões que visualizam o futuro do planeta humanitária (Sachs, 2009, p. 31).

Nesta perspectiva, é possível incentivar as novas gerações na participação do desenvolvimento de atividades que venham proporcionar 0 despertar o interesse pelos recursos florestais e faunísticos, desenvolvendo hábitos e consciência crítica sobre as questões ambientais e a responsabilidade com o futuro dos recursos florestais e faunísticos ora existente.

\section{Considerações finais}

Ao término desse trabalho, o ponto mais focante foi evidenciado pela motivação apresentada pelos professores e aprendizes, pelo interesse e participação nas atividades e pela compreensão dos conceitos trabalhados.

Neste pressuposto, a Educação Ambiental no contexto da conscientização das novas gerações, realizada por meio de atividades práticas, associada aos problemas ambientais do meio em que os professores e aprendizes estão inseridos, permitiram buscar caminhos aceitáveis para a preservação da floresta e fauna-bravia, desenvolvendo atitudes sustentáveis que Ihes possibilitam ter acesso às informações credíveis para participar ativamente na resolução da problemática ambiental atual, ocasionando assim uma mudança transformadora no comportamento das novas gerações.

Para isso, a Educação Ambiental no contexto da conscientização florestal e bravia-fauna, deve buscar acima de tudo:

a solidariedade, a igualdade e o respeito às diferenças, através da liderança democrática baseada na comunicação permanente, permitindo as novas gerações refletirem sobre as boas maneiras de convivências ambientais, conceitos, práticas e técnicas pedagógicas, que podem proporcionar um convívio equilibrado entre a comunidade em geral com o seu meio ambiente onde estão inseridos (GUIMARÃ̃ES,1995). 
Assim, a escola precisa empreender maior esforço para que os aprendizes entendam basicamente que as questões ambientais envolvem além das questões que ultrapassam as fronteiras ambientais físicas, econômicas, políticas, históricas e aspectos sociais. $O$ que possibilitaria 0 aprendiz compreender de forma concisa a importância das práticas educativas na conscientização florestal e fauna bravia.

Neste pressuposto, é urgente a escola adoptar conceitos de gestão ambiental racional e participativo, viabilizado a implementação de projetos direcionados a conscientização florestal com a sua fauna-bravia como um instrumento fundamental que possibilita a mobilização das comunidades locais, visando a mudança comportamental ,desenvolvendo uma filosofia de vida ética e moral de maior relacionamento harmonioso e respeito à natureza.

É a partir desta contextualização que Sorrentino (2004), ensina que:

um dos instrumentos fundamentais no processo das práticas educativas ambientalmente sustentáveis frente aos problemas ambientais, são os professores, pois eles procuram desenvolver atividades ecologicamente ambiental que conduzam o aprendiz a serem reconhecido como parte integrante do meio em que vive, construindo conhecimento que possibilita ajudar a manter intacta os recursos florestais e faunístico, no presente e no futuro.

Para que isso aconteça, é da responsabilidade dos pais e encarregados de educação, Organização Não Governamental (ONG), comunidade em geral, sobretudo, professores, trabalharem com as novas gerações de tal forma que estabelecem forte relação entre os valores, atitudes e comportamentos, formando um verdadeiro sistema, como argumentado por Rokeach (1981 apud COELHO; GOUVEIA; MILFONT, 2006, p. 199-207), quando defendem que:

as crenças, atitudes e valores estão atrelados, formando um sistema cognitivo funcionalmente integrado; assim, uma mudança em qualquer parte deste sistema afetará outras partes e culminará em mudança comportamental.

Assim, é importante ressaltar que, para que os princípios de sustentabilidade sejam disseminados para as novas gerações, sugerimos que os recursos didácticos educacionais sejam trabalhados diariamente nos espaços virtuais e presenciais. Pois, o processo de consciência ambiental não deve ser trabalhado isoladamente, mas sim dentro de uma estratégia metodológica de ensino que engloba aulas presenciais e de reflexão, visando assegurar a todos o conhecimento que possibilita o uso racional e sustentável dos recursos florestais e faunístico. 
É diante deste pressuposto que Oliveira (2000), sugere os seguintes passos que buscam alternativas coerentes que possibilitam o planejamento escolar e coordenação multidisciplinar:

> As temáticas socioeducativas, devem ser trabalhadas diariamente pelos professores, visando legitimar sua interdisciplinaridade, formação de cidadania consciente e responsável na resolução e tomadas das decisões dos aspectos que contribuem a degradação dos recursos naturais;

> Realização de campanhas educativas, utilizando os meios de comunicação disponíveis, imprensa falada e escrita, distribuição de panfletos, cartazes que retratam a degradação/preservação e restauração de ecossistemas, a fim de informar e incentivar as novas gerações em relação à problemática ambiental vivenciada atualmente na região em estudo, bem como na terra planetária;

> Mobilização e a capacitação permanente de toda a comunidade escolar, para o desenvolvimento de atividades coerentes que possibilitam a mudança comportamental das novas gerações, visando construir conhecimento formal e informal, na perspectiva de motivar a implementação dos direitos de toda a comunidade em geral sobre os benefícios do meio ambiente (flora e fauna-bravia).

Foi neste contexto que em 1997, foi aprovada em Moçambique a lei do meio ambiente (Lei 20/97, de 1 de Outubro), que advoga que "todo o cidadão tem direito de viver num meio ambiente equilibrado assim como o dever de o defender. A materialização deste direito passa necessariamente por uma gestão corretado meio ambiente e dos seus componentes".

Para isso, é necessário informação e a vontade política, criando estratégias que possibilitam a Educação Ambiental seja trabalhada no contexto da conscientização das novas gerações na preservação da floresta e faunabravia, estabelecendo relações recíprocas e harmoniosas entre as estruturas tradicionais, administrativa, os governantes e a comunidade em geral, na perspectiva de cuidar, preservar e defendê-lo dos infractores que perigam a sua regeneração, buscando a melhor maneira de convivência com o meio ambiente.

\section{Referências}

BARBIERI, J.C.; SILVA, D. Desenvolvimento sustentável e Educação Ambiental: uma trajetória comum com muitos desafios. RAM, Revista de Administração Mackenzie (Online), São Paulo, v. 12, n. 3, 2011.

CERVO, A.L.; BERVIAN. P.A. Metodologia científica: para uso dos estudantes universitários. São Paulo: McGraw-Hill do Brasil, 1983.

BONAGURIO, A. O Meio Ambiente no espaço escolar da Educação Infantil, São Paulo;Capivari, 2009. 
COELHO, J.A.P.M.; GOUVEIA, V.V.; MILFONT, T.L. Valores humanos como explicadores de atitudes ambientais e intenção de comportamento próambiental. Psicologia em Estudo. v. 11, n. 1, 2006.

DIAS, G.F. Educação Ambiental: Princípios e Práticas. 8. Ed. São Paulo: Gaia, 2003.

GUIMARÃES, M. A dimensão ambiental na educação. Campinas, SP: Papirus, 1995.

GUARIM, V.L.M.S. Barranco Alto: Uma experiência em Educação Ambiental.

Cuiabá: UFMT, 2002.

JACOBI, P. Educação Ambiental, Cidadania e Sustentabilidade. Cadernos de Pesquisa, n.118, março/2003.

LOUREIRO, C.F.; LAYRARGUES, P.P.; CASTRO, R.S. (orgs.). Repensar a Educação Ambiental: um olhar crÖtico. SÑo Paulo: Cortez, 2009.

MAYOR, F. Preparar um futuro viável: ensino superior e desenvolvimento sustentável. Anais da Conferência mundial sobre 0 ensino superior. Tendências de educação superior para o século XXI. Paris, 1998.

MOÇAMBIQUE. Lei no 20/97 de 1 de Outubro, no 40. [Maputo], 7 de Outubro de 1997.

MUCELIN, N.I.S. VILAS BOAS, M.A.; URIBE-OPAZO, M.A.; SECCO, D. Variabilidade espacial de atributos hídricos do solo; a inserção da engenharia agrícola em projetos nacionais.cd-rom; 1; 3; Anais do XXXIII congresso Brasileiro de Engenharia Agrícola. São Paulo, 2004.

OLIVEIRA, E.M. O Que fazer Interdisciplinar. In: A Educação Ambiental uma possível abordagem. Brasília, Edições IBAMA, 2000.

REIGOTA, M. Desafios à Educação Ambiental escolar. In: JACOBI, P. et al.(orgs.).

SACHS, I. Caminhos para o desenvolvimento sustentável. Organização de Paula Yone Stroh. Rio de Janeiro: Garamond, 2002.

SORRENTINO, M. Desenvolvimento sustentável e participação: algumas reflexões em voz alta. São Paulo: Cortez, 2004. 